\title{
Evaluation of bioactive and antioxidant activities compounds isolated from Heptapleurum stellatum (Gaertn) Baill R.Rajarajeshwari ${ }^{1,2}$, T.Selvankumar ${ }^{1}$, B.Mythili Gnanamangai ${ }^{3}$, G.Gohila ${ }^{3}$ and R. Mohanraj ${ }^{3}$ \\ 1PG \& Research Department of Biotechnology, Mahendra Arts and Science College (Autonomous), Kalippatti, Namakkal-637501, Tamil Nadu, India. \\ 2PG \& Department of Biotechnology, Sengunthar Arts \& Science College, Tiruchengode, Namakkal- 637 205, Tamil Nadu, India. \\ ${ }^{3} P G$ \& Research Department of Biotechnology, K.S.Rangasamy College of Technology, \\ Tiruchengode-637215, Tamil Nadu, India. \\ ABSTRACT: Recently, Heptapleurum stellatum is commonly known in India as Umbrella tree, has a wide range of
} medicinal uses. This study aimed to evaluate the phytoconstituents, antioxidant activities, total phenolic content and its compound characterization in leaves. Phytochemical analysis was indicated the presence of alkaloids, carbohydrates, steroids, saponins, glycosides, and terpenoids. The total phenolic content was measured by folinciocalteau assay. The total antioxidant capacity was estimated spectrometrically by 1,1-diphenyl-2-picrylhydrazyl radical (DPPH), ferric reducing antioxidant power (FRAP) and $\mathrm{H}_{2} \mathrm{O}_{2}$ assay. The methanol extracts exhibited maximum antioxidant activity. A high phenolic content of $0.357-2.004 \mathrm{GAE} / \mathrm{mg}$ and potent antioxidant activity ( $\mathrm{IC}_{50}$ value $=80 \mu \mathrm{g} / \mathrm{mL}$ ) was observed in methanol leaf extract. High reducing ability in the FRAP assay ( $\mathrm{IC}_{50}$ value $=154.24 \mu \mathrm{g} / \mathrm{mL}$ ) and $\mathrm{H}_{2} \mathrm{O}_{2}$ assay (IC50 value $=110 \mu \mathrm{g} / \mathrm{mL}$ ) was also observed in methanol leaf extract of H. stellatum. Bioactive compounds were screened using GC-MS analysis. The results suggest that $H$. stellatum has promising antioxidant activity and could serve as a potential source of natural antioxidants.

KEYWORDS: Schefflera, Antioxidant, Total phenolic, Hydrogen peroxide, DPPH, GC-MS.

(C) 2017 mahendrapublications.com, All rights reserved

\section{INTRODUCTION}

Natural antioxidants have attracted a great deal of public and scientific interest because of their anticarcinogenic potential and other health-promoting effects. Plants and vegetables are good source of phenolic components, ascorbic acids, tocopherols, glutathione, vitamin $\mathrm{C}$ and vitamin E, carotenoids, flavonoids that may contribute to protection against oxidative damage. These phytochemicals from plants have been shown to possess significant antioxidant capacities that may be associated with lower incidence and lower mortality rates in of degenerative diseases in human beings such as antiallergic, anti-artherogenic, anti-inflammatory, antimicrobial, antioxidant, anti-thrombotic, cardioprotective and vasodilatory effects [1]. Schefflera J. R. Forst.\& G. Forst.isthe largest genus in Araliaceae(ca. 600-900 species) with a wide distribution in the tropics and subtropics of both northern and southern hemispheres [2].Schefflera includes all araliads with a woody habit (trees, shrubs, and woody epiphytes, hemi epiphytes or climbers), once palmately compound leaves, fused stipules extending into lingular appendage at the base of petiole, panicles that have ultimate inflorescence of umbels, capitula, racemules, or spicules, the absence of pedicle articulations, and no prickles on the vegetative organs [3]. Heptapleurum stellatum is a large genus with over 650 species of polygamous or dioecious trees, tall shrubs or climbers distributed in tropical and subtropical regions. Phytochemical studies on plants in the Heptapleureum genus have revealed the presence of alkaloids, flavonoids, tannins, steroids, saponin, glycosides, terpenoids and phenols. The ethanomedicinal uses of Heptapleureum include treatment for asthma, liver diseases, rheumatism, arthritis, sprains, fracture, stomach pain, anti-pyretic, anti-inflammatory, analgesic, migraine and general tonic [4]. Heptapleurum stellatum (Gaertn.)Baill. is widely distributed in peninsular India and Sri Lanka. In Kerala state of southern India, it is found in Silent valley and Agasthyamalai Hills. Ethano medicinal uses of Heptapleurum stellatum revealed that it is used to cure neurological weakness [5] and a belief that the bark ash is used to control evil spirit [6]. Recently there has been an increasing interest in free radicals in biological systems and their implied role as causative agents in a variety of pathological physiologies. Free radicals can be described as any species, which is capable of independent existence and contained one or more unpaired electrons, which makes them highly reactive. They promote beneficial oxidation to generate energy and kill microbial invaders. But in excess they cause harmful oxidation that can damage cell membrane and even cell death. Antioxidant nutrients have the ability to scavenge free radicals in the system and neutralize them before they do any damage to body cells.

*Corresponding Author: selvankumar75@gmail.com

Received: 10.10 .2017

Accepted: 05.12.2017

Published on: 12.12 .2017

Rajarajeshwari et al., 
Most plants have protective biochemical functions of naturally occurring antioxidants in the cells. Many secondary compounds and enzymes of higher plants have been demonstrated with in vitro experiments to protect against oxidative damage by inhibiting or quenching free radicals.

\section{MATERIALS AND METHODS \\ 2.1 Collection of plant materials}

The plant samples were collected from Tiruchengode, Namakkal Dt. The specimens were preserved, identified and authenticated by the Botanical Survey of India Southern circle, Coimbatore as Heptapleurum stellatum (Gaertn.) Baill. (Araliaceae) BSI/SRC/5/23/2016/Tech./850.

\subsection{Preparation of extracts}

The collected plant parts were dried under shade or may be in oven to remove the water content from the plants to get dried powder. The dried plant leaves were extracted with solvents like ethanol, methanol, formaldehyde, chloroform, aqueous, ethyl acetate, petroleum, toluene for phytochemical screening and to identify antioxidant activities. The extract was prepared by adding $10 \mathrm{~g}$ of leaf powder in $100 \mathrm{~mL}$ of solvent. The mixture was kept in shaking condition for about 24-48 h. Then the extractions were dried by pouring it in petri dishes and dry them properly. The dried plates were then scraped and the powder were collected and stored in proper containers.

\subsection{Phytochemical Screening}

Qualitative phytochemical analysis of the crude powder and different solvent extracts were determined using standard procedures [7].

\subsubsection{Alkaloids (Wagner's test)}

About $10 \mathrm{mg}$ of extract was taken and few drops of Wagner's reagent were added and the formation of a reddish brown precipitate indicates the presence of alkaloids.

\subsubsection{Flavanoids (Lead acetate test)}

$10 \mathrm{mg}$ of extract was taken and few drops of $10 \%$ lead acetate solution were added. The appearance of yellow colour indicates the presence of flavonoids.

\subsubsection{Tannins (Ferric chloride test)}

$5 \mathrm{mg}$ of extract was taken and $0.5 \mathrm{~mL}$ of $5 \%$ ferric chloride was added. The development of dark bluish black colour indicates the presence of tannins.

\subsubsection{Phlobatannins (HCl test)}

Formation of a red precipitate when the aqueous extract of plant sample was boiled with aqueous $\mathrm{HCl}$ $(1 \%)$ indicated the presence of phlobatannins.

\subsubsection{Steroids and sterols (Salkowski's test)}

Five mg of extract was dissolved in $2 \mathrm{~mL}$ of chloroform and an equal volume of concentrated $\mathrm{H}_{2} \mathrm{SO}_{4}$ was added along the sides of the test tube. The upper layer turns red and lower layer turns yellow with green fluorescence, indicating the presence of the steroids and sterol compounds in the extract.

2.3.6 Carbohydrates (Fehling's test)

$5 \mathrm{~mL}$ of Fehling's solution was added to $0.5 \mathrm{mg}$ of extract and boiled in a water bath. The formation of yellow or red precipitate indicates the presence of reducing power.

\subsubsection{Saponins (Foam and frothing test)}

Foam test

$0.5 \mathrm{mg}$ of extract was diluted with $20 \mathrm{~mL}$ distilled water and shaken well in a graduated cylinder for 15 mins. The formation of foam to a length of $1 \mathrm{~cm}$ indicated the presence of saponins.

\subsubsection{Frothing test}

$0.2 \mathrm{~mL}$ of the extract was mixed with $5 \mathrm{~mL}$ of distilled water and kept under shaking for 20 mins. Persistence foam indicated the presence of saponins.

2.3.9 Glycosides

$0.5 \mathrm{mg}$ of extract was dissolved in $1 \mathrm{~mL}$ of water and then aqueous $\mathrm{NaOH}$ solution was added. Formation of yellow colour indicates the presence of glycosides.

\subsubsection{Anthraquinone (Borntragers test)}

About $0.5 \mathrm{gm}$ of the extract was taken into a dry test tube and $5 \mathrm{~mL}$ of chloroform was added and shaken for 5 minutes. The extract was filtered and the filtrate was shaken with an equal volume of $10 \%$ ammonia solution. A pink violet or red colour in the lower layer indicates the presence of anthraquinone.

2.3.11 Terpenoids (Salwokski test)

$0.5 \mathrm{gm}$ of the extract was dissolved in $2 \mathrm{~mL}$ of chloroform, and then $3 \mathrm{~mL}$ of concentrated $\mathrm{H}_{2} \mathrm{SO}_{4}$ was added. A reddish brown color in interphase indicates the presence of terpenoids.

\subsubsection{Phenol (Sodium Hydroxide test)}

$5 \mathrm{mg}$ of extract was dissolved in $0.5 \mathrm{~mL}$ of $20 \% \mathrm{H}_{2} \mathrm{SO}_{4}$ solution. Followed by addition of few drops of aqueous sodium hydroxide solution, it turns blue which the presence of phenols.

\subsection{Determination of Antioxidant Activity \\ 2.4.1 Dot-blot rapid screening assay}

The rapid screening assay was performed by the standard method [8]. Aliquots of plant extracts were spotted carefully on TLC plates and dried for $3 \mathrm{~min}$. The sheets bearing the dry spots were placed upside down for 10 seconds in a $0.4 \mathrm{mM}$ DPPH solution in methanol and the layer was dried. The stained silica layer revealed a purple background with yellow spots, which showed radical scavenging capacity. The ability of the plant extracts to scavenge the DPPH radical was tested in a rapid dot-blot screening and quantified using a spectrophotometer.

\subsubsection{DPPH free radical scavenging activity}

Radical scavenging activity by DPPH method was evaluated according to the standard procedure [9]. Aliquots of standard $(20-100 \mu \mathrm{g} / \mathrm{mL})$ and plant extracts $(20-100 \mu \mathrm{g} / \mathrm{mL})$ were taken and the volume was made up to $1000 \mu \mathrm{l}$ using distilled water. To this two $\mathrm{mL}$ of DPPH was added and the tubes were kept under dark for 30 minutes. The incubated mixture was read at 517 $\mathrm{nm}$ using a spectrophotometer. Percentage of radical scavenging was calculated based on the extent of reduction in the color.

Percentage of radical scavenging activity $=$ AcAs $/$ Ac $\times 100$

\section{Rajarajeshwari et al.,}


Where, $\mathrm{Ac}=$ absorbance of the control; As = absorbance of the sample.

2.4.3 Ferric reducing antioxidant power (FRAP) assay Total antioxidant activity by FRAP assay was determined by the modified method [10]. The ability to reduce ferric ions was measured using standard method [11]. The stock solutions of phosphate buffer saline $(0.2$ M. pH-7.4) were prepared. An amount of $200 \mu \mathrm{l}$ extracted samples or standard (Quercitin/ ascorbic acid) were mixed with $1 \%$ potassium ferricyanide and potassium phosphate buffer in test tubes. Blank samples were prepared with buffer alone. Then the samples were centrifuged at $3000 \mathrm{rpm}$ for 10 minutes. From the centrifuged sample the supernatant of about $2.5 \mathrm{~mL}$ was taken and mixed with $2.5 \mathrm{~mL}$ of distilled water and $0.5 \mathrm{~mL}$ Ferric chloride. The absorbance of the samples was determined against blank at $595 \mathrm{~nm}$. The standard curves were plotted using absorbance of the standards and samples.

Percentage of radical scavenging activity $=$ Ac-As $/$ Ac $\times$ 100

Where, Ac=absorbance of control; As= absorbance of the sample.

\subsubsection{Hydrogen peroxide reducing assay}

The hydrogen peroxide scavenging assay was carried out using the standard procedure [12]. This method is based on the reduction of $\mathrm{H}_{2} \mathrm{O}_{2}$, a weak oxidizing agent which can serve as a possible source of $\mathrm{OH}$ free radical. A solution of hydrogen peroxide $(40 \mathrm{mM})$ was prepared in phosphate buffer ( $\mathrm{pH} 7.4$ ). Different dilutions of test compound in distilled water $(20,40,60,80,100 \mu \mathrm{g} / \mathrm{mL})$ were added to a hydrogen peroxide solution $(1.0 \mathrm{~mL}$, $40 \mathrm{mM}$ ) and after $10 \mathrm{~min}$ the absorbance of the reaction mixture was recorded at $230 \mathrm{~nm}$ against a blank solution containing the phosphate buffer without hydrogen peroxide. The percentage of hydrogen peroxide scavenging of both test compounds and standard compounds were calculated as:

$\%$ Scavenging $[\mathrm{H} 2 \mathrm{O} 2]=[(\mathrm{Ac}-\mathrm{As}) / \mathrm{Ac}] \times 100$

Where $A c=$ The absorbance of control reaction As $=$ The Absorbance of test or standard sample.

The $\mathrm{IC}_{50}$ value of the samples, were calculated using dose inhibition curve. The lower absorbance of the reaction mixture indicated higher free radical activity.

\subsubsection{Total Phenolic Content Assay}

The total phenolic contents were determined using Folin-Ciocalteau reagent [13].Different concentrations of the extracts $(0.5 \mathrm{~mL})$ or gallic acid (standard phenolic compound) was mixed with $5 \mathrm{~mL}$ of Folin-Ciocalteau reagent and aqueous $1 \mathrm{M}$ sodium carbonate $(4 \mathrm{~mL})$. The mixture was allowed to stand for 15 minutes and the total phenolic contents were measured at $756 \mathrm{~nm}$ with a UV-VIS double beam spectrophotometer (Systonic, Ahmedabad, India). The phenolic contents are expressed in terms of Gallic acid equivalent $(\mathrm{mg} / \mathrm{g}$ of extracts), which is a common reference compound

\section{Rajarajeshwari et al.,}

\subsection{Identification of Compounds}

The presence of phytochemical constitutes has been reported from species of Araliaceae. The phytochemical investigation of methanolic extracts of H. stellatum was performed on a GC-MS equipment (Perkin Elmer GC model: clarus 680; Mass Spectrometer: clarus 600). This method is used for identifying volatile compounds in complex mixtures. The extraneous mass spectral peaks commonly arise from co-eluting compounds, column bead, and ion-chamber contaminants. The height of the peak determines the compounds present in the sample. The high peak represents the highest amount of compound present in the given sample. The Clarus $680 \mathrm{GC}$ was used in the analysis which employed with a fused silica column, packed with Elite-5MS (5\% biphenyl 95\% dimethylpolysiloxane, $30 \mathrm{~m} \times 0.25 \mathrm{~mm}$ ID $\times 250 \mu \mathrm{mdf}$ ) and the components were separated using Helium as carrier gas at a constant flow of $1 \mathrm{~mL} / \mathrm{min}$. The injector temperature was set at $260{ }^{\circ} \mathrm{C}$ during the chromatographic run. The $1 \mu \mathrm{L}$ of extract sample injected into the instrument the oven temperature was as follows: $60^{\circ} \mathrm{C}(2 \mathrm{~min})$; followed by $300{ }^{\circ} \mathrm{C}$ at the rate of $10^{\circ} \mathrm{C} \mathrm{min}-1$; and $300^{\circ} \mathrm{C}$, where it was held for $6 \mathrm{~min}$. The mass detector conditions were: transfer line temperature $240{ }^{\circ} \mathrm{C}$; ion source temperature $240{ }^{\circ} \mathrm{C}$; and ionization mode electron impact at $70 \mathrm{eV}$, a scan time $0.2 \mathrm{sec}$ and scan interval of $0.1 \mathrm{sec}$. The fragments is from 40 to $600 \mathrm{Da}$. The spectrums of the components were compared with the database of the spectrum of known components stored in the GC-MS NIST (2008) library [14].

\section{Mass Condition (EI)}

$\begin{array}{ll}\text { Solvent Delay } & : 2.00 \mathrm{~min} \\ \text { Transfer Temp } & : 240{ }^{\circ} \mathrm{C} \\ \text { Source Temp } & : 240{ }^{\circ} \mathrm{C} \\ \text { Scan } & : 50 \text { to } 600 \mathrm{Da}\end{array}$

\section{RESULTS AND DISCUSSION} 3.1 Phytochemical Screening

In the present study, the phytochemical screening of $H$. stellatum leaf extracts showed the presence of alkaloids, carbohydrates, steroids, saponins, glycosides, and terpenoids (Table 1). Phytochemical analysis of Schefflera racemosa leaf extracts showed positive results for saponins, tannins, flavonoids, cardiac glycosides, steroids, reducing sugars and terpenoids. Phytochemicals refer to a wide variety of compounds made by plants and are mainly used to describe those compounds that may affect human health. Secondary metabolites are the classes of compounds which are known to show curative activity against several human ailments [15]. The phytochemical analysis conducted on the extract of $B$. nakhonphanomensis revealed the presence of constituents that are known to exhibit medicinal as well as physiological activities [16]. 


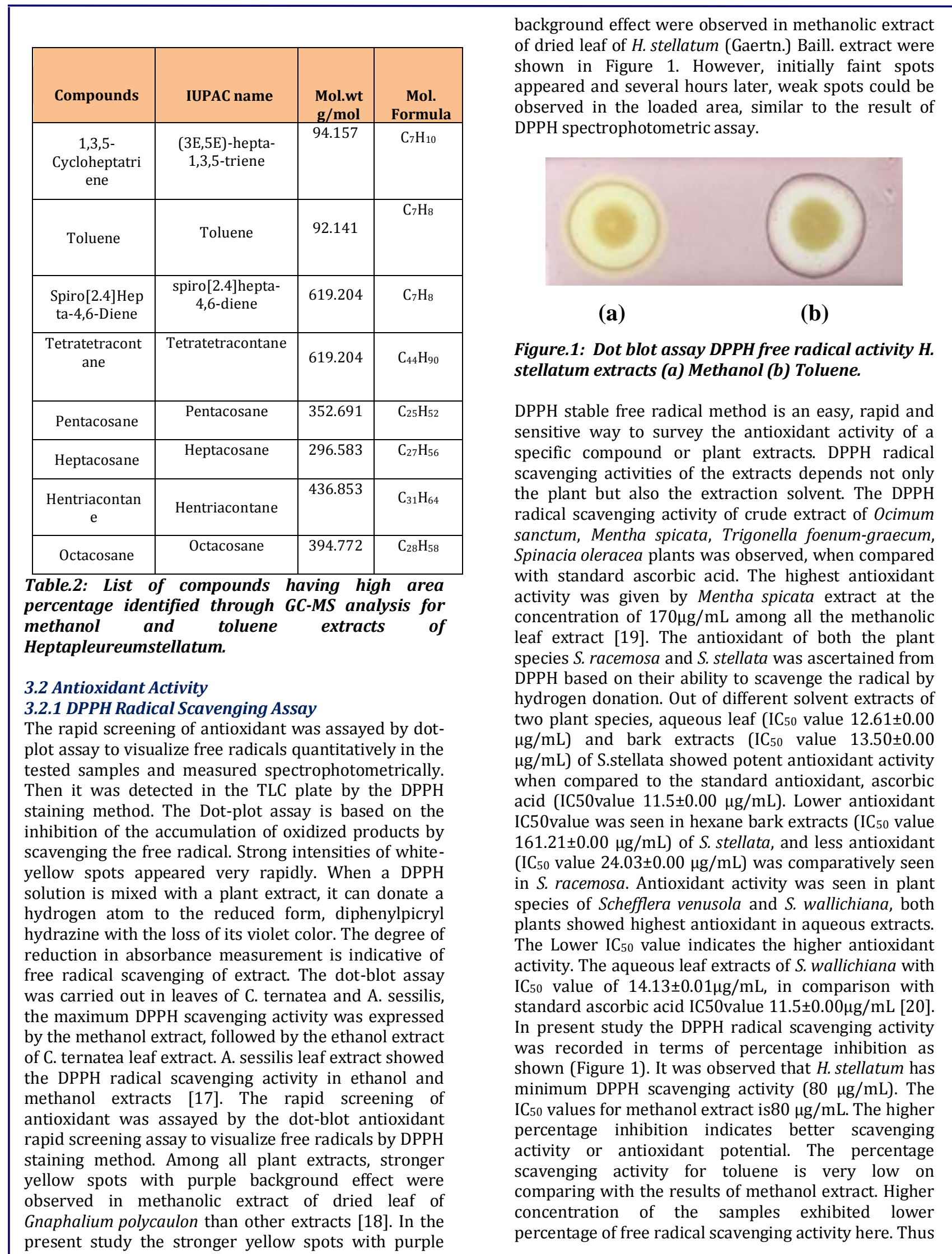

\section{Rajarajeshwari et al.,}


the $\mathrm{IC}_{50}$ values can't be determined in this activity (Figure.2).

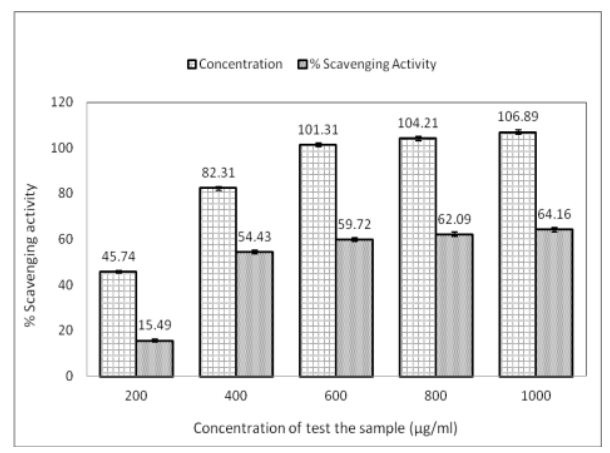

Figure.2: Determination of percentage radical scavenging activity for methanol extract of $H$. stellatum using DPPH antioxidant assay.

The comparative results suggest higher antioxidant activity was seen in methanolic leaf extracts of $H$. stellatum (Gaertn.) Baill. in DPPH radical scavenging assay. These results help to justify the use of the plants in the treatment of cancer. In fact, antioxidants participate in the treatment of cancer by the capacity to scavenge free radicals [21-23]. Plants which have shown a good antioxidant activity are potential sources for isolating new antioxidant molecules.

\subsubsection{FRAP Assay}

FRAP assay evaluates total antioxidant power and is chosen to assess the presumable effects of medicinal plants [24]. Frap assay treats the antioxidants in the sample as a reductant in a redox-linked colorimetric reaction. The reducing ability of various solvent extracts in different parts of both $S$. venulosa and $S$. wallichiana were examined. Maximum reducing ability at 100 $\mu \mathrm{g} / \mathrm{mL}$ was seen in aqueous flower extracts $S$. venulosa and $S$. wallichiana, whereas low reducing ability were seen in ethanolic leaf extract of $S$. venulosa and chloroform extract of bark of $S$. wallichiana. Reducing the capacity of a compound may serve as an indicator of its potential antioxidant capacity [25]. Compounds with reducing power indicate that they are electron donors and can reduce oxidized intermediates of lipid peroxidation process. They can act as primary as well as secondary antioxidants [26]. In the present study, the trends for ferric ion reducing activities of $H$. stellatum are shown. The absorbance of $H$. stellatum clearly increased, due to the formation of the $\mathrm{Fe}^{2+}$ complex with increasing concentration. The toluene and methanol extracts showed increased ferric reducing power with the increased concentration as standard. Hence they should be able to donate electrons to free radicals stable in the actual biological and food system. Figure. 3 shows the percentage scavenging activity of methanolic extract sample against the concentration of the sample. The scavenging activity of the sample decreases as the concentration of the sample increases.

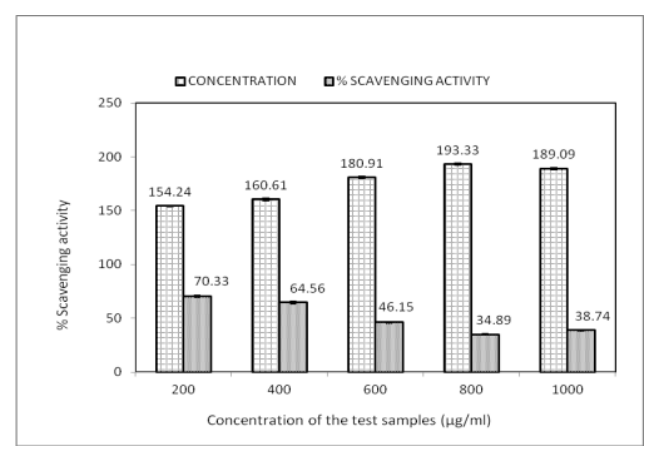

Figure.3: Determination of Percentage Radical scavenging activity for Methanol extract of $\boldsymbol{H}$. stellatum using FRAP antioxidant assay

The highest scavenging activity obtained is $70.33 \%$ for the concentration of $154.24 \mu \mathrm{g} / \mathrm{mL}$. Likewise the lowest scavenging activity is $34.89 \%$ for $193.33 \mu \mathrm{g} / \mathrm{mL}$ concentration of the methanol sample in the Figure. 3 and Figure.4 depicts the positive results for the toluene extract. The absorbance values increases for both the samples which indicates the positive result for this ferric reducing assay. From these results it can be determined that this samples can be tested for anticancerous activity.

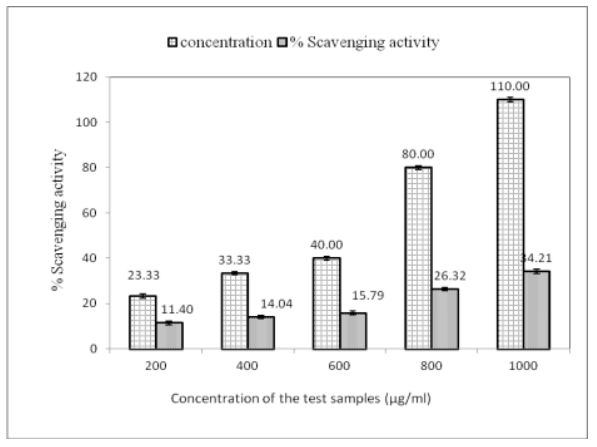

Figure.5: Determination of percentage scavenging activity for methanol extract of $H$. stellatum using $\mathrm{H}_{2} \mathrm{O}_{2}$ antioxidant assay.

3.2.3 Hydrogen Peroxide Assay

Hydrogen peroxide occurs naturally at low concentration levels in the air, water, human body, plants, microorganisms, food and beverages. It is widely used as a bleaching agent in the textile, paper and pulp industries. Human beings exposed to $\mathrm{H}_{2} \mathrm{O}_{2}$ indirectly via the environment are estimated at $0.28 \mathrm{mg} / \mathrm{kg} /$ day with intake from leaf crops contributing most to this exposure [27]. Hydrogen peroxide enters the human body through inhalation of vapour or mist and through eye or skin contact. In the body, $\mathrm{H}_{2} \mathrm{O}_{2}$ is rapidly decomposed into oxygen and water and this may produce hydroxyl radicals $\left(\mathrm{OH}^{-}\right)$that can initiate lipid peroxidation and cause DNA damage [28]. In present study the scavenging ability of toluene and methanolic extracts of H. stellatum on hydrogen peroxide is shown in Figure.5. Both toluene and methanol extracts of $H$.

\section{Rajarajeshwari et al.,}


stellatum were subjected to hydrogen peroxide activity. Hydrogen peroxide itself is not very reactive but it can sometimes be toxic to cell as it may give rise to hydroxyl radical $\mathrm{H}_{2} \mathrm{O}_{2}$ is very important for antioxidant defense in cell or food systems. Hydrogen peroxide is a weak oxidizing agent and can inactivate a few enzymes directly, usually by oxidation of essential thiol $(-\mathrm{SH})$ groups. According to [29], hydrogen peroxide can cross cell membrane rapidly and, once inside the cell, hydrogen peroxide can probably react with $\mathrm{Fe}_{2+}$, and possibly $\mathrm{Cu}_{2+}$ ions to formhydroxyl radicals and this may be the origin of many of its toxic effects. It is therefore biologically beneficial for cells to control the accumulated hydrogen peroxide. The results of $\mathrm{H}_{2} \mathrm{O}_{2}$ assay reveals that radical scavenging activity is not obtained in toluene extracts of the sample and the results for methanol extract of the test sample were given in (Figure.5). The highest scavenging activity is obtained for the concentration $110 \mu \mathrm{g} / \mathrm{mL}$ as $34.21 \%$. Figure. 6 gives the results for toluene extract of the test sample. The scavenging activity for this extract is very low. Thus this sample doesn't give the results for $\mathrm{IC}_{50}$ values were unable to determine

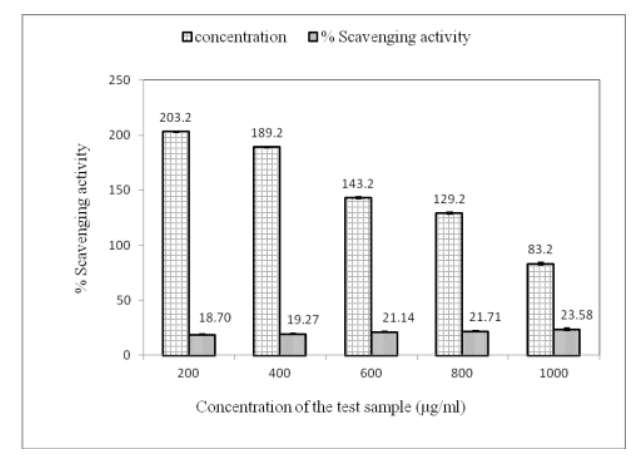

Figure.6: Determination of percentage scavenging activity for toluene extract of $\mathrm{H}$. stellatum using $\mathrm{H}_{2} \mathrm{O}_{2}$ antioxidant assay.

3.2.4 Total phenolic content assay

Phenolics are ubiquitous secondary metabolites in plants possessing a wide spectrum of biochemical activities such as antioxidant, antimutagenic and anticarcinogenic activities. It is reported that phenolics are responsible for the variation in the antioxidant activity of the plant. They exhibit antioxidant activity by inactivating lipid free radicals. The total phenolic content was measured between two plant species of Araliaceae i.e. S. venusola and $S$. wallichiana. High phenolic content was seen in aqueous flower extract of $S$. venulosa and $S$. wallichiana, whereas low content was seen in hexane leaf of both the plants. In present study the total phenolic content of $H$. stellatum is represented in Figure.7. The amounts of total phenolics were measured by Folin-Ciocalteu method. This result shows the comparison of methanol and toluene extracts of $H$. stellatum. The phenolic content of methanol extract gradually increases as the concentration increases. The higher phenolic content was obtained for the concentration of about $500 \mu \mathrm{g} / \mathrm{mL}$. The phenolic content of the sample ranges from 0.36 to $2.0 \mathrm{mg}$ Gallic acid equivalent/mg. The toluene extracts of the sample shows only about 0.68 to $0.77 \mathrm{mg}, \mathrm{GAE} / \mathrm{mg}$. the considerable results of phenolic content are may be due to environmental related factors like maturity period, climate, location, temperature, fertility, diseases. In addition, rainfalls are also reported to affect the phenolic content. The presence of different phenolic compounds may be the cause in the variation of total phenolics in the plant extracts. It is observed that most of the plant samples are rich in flavonoids. This plant also rich in flavonoids in some of the solvent extracts. The results obtained were higher than those obtained from the present study. The values obtained were from 0.357 to $2.004 \mathrm{GAE} / \mathrm{mg}$. these results were nearly similar but are high values.

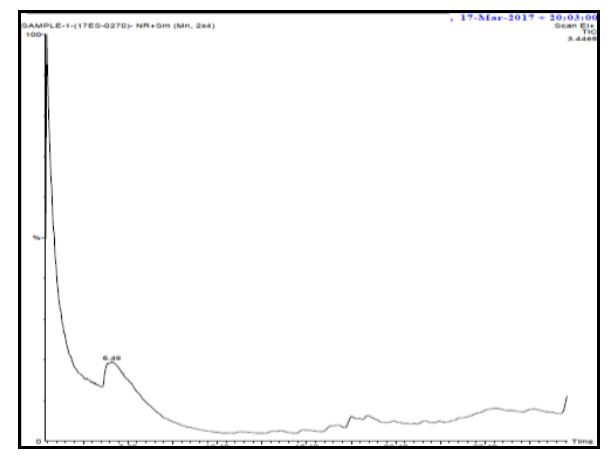

Figure. 8: Chromatogram results for methanol extract of $\mathrm{H}$. stellatum

Phenolics are the most widespread secondary metabolite in plant kingdom [30]. These diverse groups of compounds have been received much attention as potential natural antioxidant in terms of their ability to act as both efficient radical scavengers and metal chelator. It has been reported that the antioxidant activity of phenol is mainly due to their redox properties, hydrogen donors and singlet oxygen quenchers [31].

\subsubsection{Compound identification}

GC-MS studies have been increasingly applied for the analysis of medicinal plants as this technique has proved to be a valuable method for the analysis of nonpolar components and volatile essential oils, fatty acids, lipids and alkaloids. GC/MS data revealed that the ethanolic extract of $B$. nakhonphanomensis contained three major chemical constituents, i.e., inositol, phenol, and alpha-tocopherol. The present results were pertaining to GC-MS analysis of the methanol and toluene extract of $H$. stellatum, which leads to the identification of a number of compounds. These compounds were identified through mass spectrometry attached with GC. The chromatogram results for methanol extract of $H$. stellatum reveals 3 different compounds, in which high area occupied by $1,3,5$ cycloheptatriene and lowest area occupied by spiro $(2,4)$ Hepta-4,6-diene and toluene compound (Figure.8). The toluene extract reveals 13 different compounds in

\section{Rajarajeshwari et al.,}


which 5 compounds shows higher area (Octacosane, Tetratetracontane, Pentacosane, Heneicosane and Hentriacontane) whose molecular structures were given in table 2

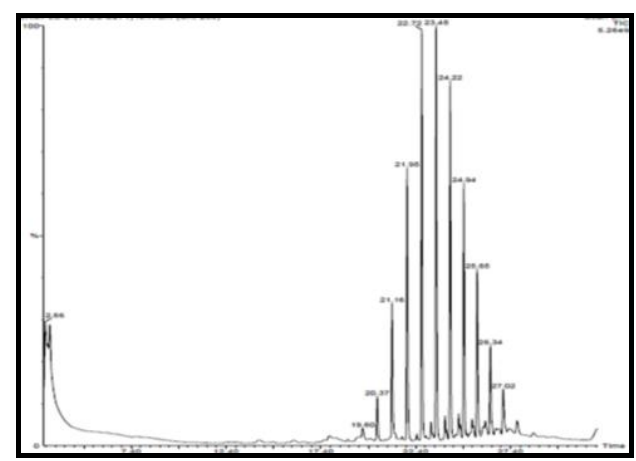

Figure.9: Chromatogram results for toluene extract of H. stellatum

\section{CONCLUSION}

Antioxidants play an important role as health protecting factor. Scientific evidence suggests that antioxidants reduce the risk for chronic diseases including cancer and heart disease. Primary sources of naturally occurring antioxidants are whole grains, fruits and vegetables. Plant-sourced antioxidants like vitamin $\mathrm{C}$, vitamin E, carotenes, phenolic acids etc. have been recognized as having the potential to reduce disease risk. Most of the antioxidant compounds in a typical diet are derived from plant sources and belong to various classes of compounds with a wide variety of physical and chemical properties. Any oxidant entering the biological system can maximally manifest its damaging effects only after entry into the cellular environment and by passing the endogenous antioxidant system. For the entry into the cell or its organelles, an oxidant needs to cross the membrane barriers (both plasma membrane and internal membranes). The selection of medical plant as a source for anticancerous activity is that they can be a promising source, cost-effective reliable and possess least side effects. The results in this study are agreed to some extent with the traditional uses of the plant investigated. Thus it further supports the idea that $H$. stellatum can be a promising source of potential anticancer and antioxidants. The phytochemical, and antioxidant studies revealed better results for the methanol extract of $H$. stellatum plant leaves. The phytochemical analysis gives positive results for alkaloids, saponins, terpenoids, cardiac glycosides, carbohydrates and phenols. These kinds of plants should be given with lot of importance and their bioactive properties should be studied in an elaborative manner and should be documented. Specifically, preservation of medicinal plants is in urgent need to protect biological diversity for the betterment of future generation.
Table. 1: Phytochemical screening of Heptapleureumstellatum leaf extracts

\begin{tabular}{|c|c|c|c|c|c|c|c|c|c|}
\hline $\begin{array}{l}\stackrel{n}{0} \\
\frac{0}{0} \\
\stackrel{0}{0}\end{array}$ & 号 & 总 & 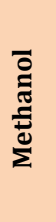 & 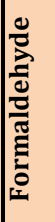 & 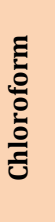 & 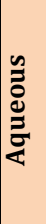 & 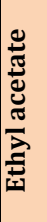 & 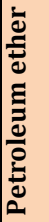 & 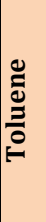 \\
\hline Alkaloids & WT & + & + & + & + & + & + & - & + \\
\hline Flavonoids & LAT & - & - & - & - & - & - & - & + \\
\hline Tannins & FCT & - & - & - & - & - & - & - & + \\
\hline Carbohydrate & FT & + & + & + & + & - & + & - & - \\
\hline Steroids\& Sterols & ST & + & + & + & + & + & + & - & - \\
\hline Saponin & FFT & + & + & + & + & + & + & - & + \\
\hline Glycosides & GT & + & + & + & + & + & + & - & + \\
\hline Anthraquinones & BT & - & - & - & - & - & - & - & - \\
\hline Terpinoids & ST & + & + & + & + & + & + & - & + \\
\hline Phenols & SHT & - & - & - & - & - & - & - & + \\
\hline Phlobatannins & HT & - & - & - & - & - & - & - & - \\
\hline
\end{tabular}

WT-Wagners test; LAT-Lead Acetate Test

FCT-Ferric Chloride Test; FT-Fehlings Test

ST-Salkowski Test;FFT-Foam \& Frothing Test

GT-Glycosides Test;BT-Borntragers test

SHT-Sodium Hydroxide Test;HT-HCl Test

\section{REFERENCES}

[1]. Manach C, Mazur A, Scalbert A 2005. Polyphenols and prevention of cardiovascular diseases. Curr. Opinion in Lip., 16(1) 77-84.

[2]. Frodin DG, Lowry II PP, Plunkett GM. 2010. Schefflera (Araliaceae): Taxonomic history, overview and progress. Plant Diversity and Evolution 128, 561-595.

[3]. Frodin DG 1975. Studies in Schefflera (Araliaceae): The Cephaloschefflera complex. Journal of the Arnold Arboretum 56, 427-448.

[4]. Deepa RH, Nalini MS 2013. Phytochemical screening, total phenolic content and invitro antioxidant studies of leaf, bark and flower extracts of Schefflera spp. (Araliaceae). Journal of applied pharmaceutical science, 3(11), 094-098.

\section{Rajarajeshwari et al.,}


[5]. Roa JK, Reddi TVVS, Kumar OA 2011. Ethanobotany of stem bark of certain plants of Visakhapatnam District, Andra Pradesh, Current Botany, 2(5), 1-6.

[6]. Kadavul K, Dixit AK. 2009. Ethanomedicinal studies of the woody species of Kalrayan and Shrevarayan Hills, Eastern Ghats, Tamil Nadu. Indian Journal of Traditional Knowledge, 8(4), 592-597.

[7]. Harborne JB 1984. Phytochemical methods. Edn 2. Champion and Hall Publishers, London,84-196.

[8]. Rivas SC, Espin JC, Wichers, HJ 2000.An easy and fast test to compare total free radical scavenger capacity of foodstuffs. Phytochem Anal, 11, 330338.

[9]. Pannangpetch P, Laupattarakaseem P et al., 2007. Antioxidant activity and protective effect against oxidative hemolysis

of Clinacanthusnutans(Burm.f).Lindau.Songklanalari n J. Sci. Technol., 29(1),1-9.

[10]. Benzie IFF, Strain JJ 1996. Ferric reducing ability to plasma (FRAP) a measure of antioxidant power: The FRAP assay. Annals of Biochemistry, 239, 70-76.

[11]. Yang J, Guo J, Yuan J 2008. In vitro antioxidant properties of rutin, Food Science and Technology, 41, 1060-1066.

[12]. Jayaprakash GK, Singh RP, Sakariah 2001. Antioxidant activity of grape seed extracts on peroxidation models in-vitro, Journal of Agriculture and Food Chem, 55, 1018-1022.

[13]. McDonald S, Prenzeler PD, Antolovich M, Robards K 2001. Phenolic content and antioxidant activity of olive extracts. Food chemistry 73,73-84.

[14]. Hannelore K, Katja D, Wolfram G, Peter JO 2008. Automated GC-MS analysis of free amino acids in Biological fluids. Journal of Chromatography B, $870(2), 222-232$.

[15]. Deepa RH, Nalini MS 2014. Evaluation of phytochemicals, total phenolics and antioxidant of Schefflera spp. (Araliaceae) from southern India. Journal of Pharmacognosy and phytochemistry, pp. 10-14.

[16]. William P, Wannachai C 2017. GC-MS Analysis and antioxidant activity of Bauhinia nakhonphanomensis leaf ethanolic extract. Pharmcogn J., 9(5), 663-667.

[17]. Balachandar B, Jayachitra Y, Paramasivam S, Arulkumar A 2013. Evaluation of Antioxidant Activity of Clitoria ternatea and Alternanthera sessilis Plant Extracts Using Model System for Yeast Cells. African Journal of Basic \& Applied Sciences, 5 (3), 134-138.

[18]. Shanmugapriya K, Senthil Murugan T, Udayabhanu J Thayumanavan T 2017. Antioxidant Investigation of Dried Methanolic Extracts of Gnaphalium polycaulon Pers, An Indian Folkloric Ethnomedicinal Plant of the Nilgiri, Tamil Nadu, India. American Journal of Phytomedicine and Clinical Therapeutics, 5 (1:3).
[19]. Anjali S, Sheetal, S 2013. Phytochemical analysis and free radical scavenging potential of herbal and medicinal plant extract. Journal of pharmacognosy and phytochemistry, 2(4) 22-29.

[20]. Hebbar RD, Nalini MS 2013. Phytochemical screening, total phenolic content and in vitro antioxidant studies of leaf, bark and flower extracts of Schefflera spp. (Araliaceae). Journal of Applied Pharmaceutical Science, 3 (11), 094-098.

[21]. Cai Y., Luo Q., Sun M. and Harold C 2004. Antioxidant activity and phenolic compounds of 112 traditional Chinese plants associated with anticancer". Life Sciences, pp. 2157-2184.

[22]. Kaur M, Chandel M, Kumar S, Kumar N, Singh B, Kaur S 2010. Modulatory role of alizarin from Rubiacordifolia against genotoxicity of mutagens, Food and Chemical Toxicology, 48, 320-325.

[23]. Wang G, Reed E, Li QQ 2006. Molecular basis of cellular response to cisplatin chemotherapy in non-small cell lung cancer. Oncology Rep, 12,955-65.

[24]. Szollosi R, Varga IS 2002. Total antioxidant power in some species of Labiatae (Adaptation of FRAP method). Acta Biol. Szwged. 46(3-4) 125127.

[25]. Meir S, Kanner J, Akiri B, Philosoph-Hadas S 1995. Determination and involvement of aqueous reducing compounds in oxidative potential of 124 Egyptian plants with emphasis on the action of Punica granatum leaf extracts on rats. International food research journal, 8: 535542.

[26]. Chanda S, Dave R, 2009. In vitro models for antioxidant activity evaluation and some medicinal plants processing antioxidant properties. An overview. African journal of microbiology research, 3/913, 981-996.

[27]. Kumawat BK, Gupta M, Tarachand, Singh Y 2012. Invitro antioxidant activity of various successive extracts of leaves of Balanites aegyptiaca (L.)Delite by scavenging of $\mathrm{H}_{2} \mathrm{O}_{2}$.Indian J.Nat.Prod., 3, 28(2).

[28]. Alagumanivasagam G, Pasupathy R, Kottaimuthu A, Manavalan R 2012. A Review on in-vitro antioxidant methods. International Journal of Pharmaceutical and Chemical Sciences, 1(2):662674.

[29]. Miller MJ, Sadowskwa-Krowicka H, Chotinaruemol S, Kakkis JL, Clark DA 1993. Amelioration of chronic ileitis by nitric oxide synthase inhibition. J. Pharmacol. Exp. Ther. 264 (1) 11-16.

[30]. Kiritikar KR, Basu LM, Basu, BD 1988. Indian medicinal plants, Allahabad, 26-39.

[31]. Rice-Evans CA, Miller NJ, Bolwell PG, Bramley PM, Pridham JB 1995. The relative antioxidant activities of plant derived polyphenolic flavonoids. Free Radic Res., 22, 375-383.

Rajarajeshwari et al., 